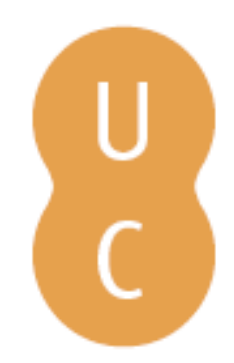

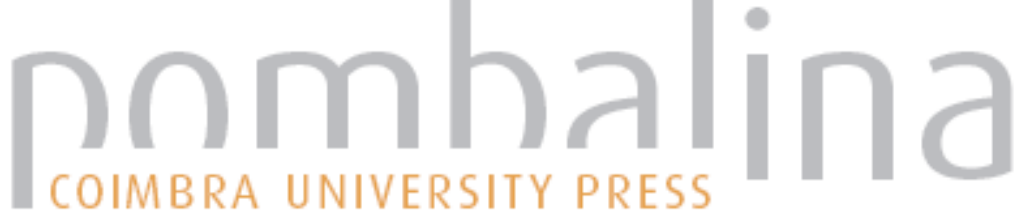

\section{As histórias no Asinus Aureus de Apuleio e a sua relação com o romance}

Autor(es): $\quad$ Teixeira, Cláudia Amparo Afonso

Publicado por: Centro de Estudos Clássicos e Humanísticos

URL

persistente: URI:http://hdl.handle.net/10316.2/39255

DOI: $\quad$ DOI:http://dx.doi.org/10.14195/978-989-26-1229-4_13

Accessed : $\quad$ 26-Apr-2023 09:55:05

A navegação consulta e descarregamento dos títulos inseridos nas Bibliotecas Digitais UC Digitalis, UC Pombalina e UC Impactum, pressupõem a aceitação plena e sem reservas dos Termos e Condições de Uso destas Bibliotecas Digitais, disponíveis em https://digitalis.uc.pt/pt-pt/termos.

Conforme exposto nos referidos Termos e Condições de Uso, o descarregamento de títulos de acesso restrito requer uma licença válida de autorização devendo o utilizador aceder ao(s) documento(s) a partir de um endereço de IP da instituição detentora da supramencionada licença.

Ao utilizador é apenas permitido o descarregamento para uso pessoal, pelo que o emprego do(s) título(s) descarregado(s) para outro fim, designadamente comercial, carece de autorização do respetivo autor ou editor da obra.

Na medida em que todas as obras da UC Digitalis se encontram protegidas pelo Código do Direito de Autor e Direitos Conexos e demais legislação aplicável, toda a cópia, parcial ou total, deste documento, nos casos em que é legalmente admitida, deverá conter ou fazer-se acompanhar por este aviso. 
FRANCISCO DE OLIVEIRA

PAOLO FEDELI

DELFIM LEÃO

Coordenadores

\section{- ROMANCE ANTIGO ORIGENS DE UM GÉNERO LITERÁRIO}

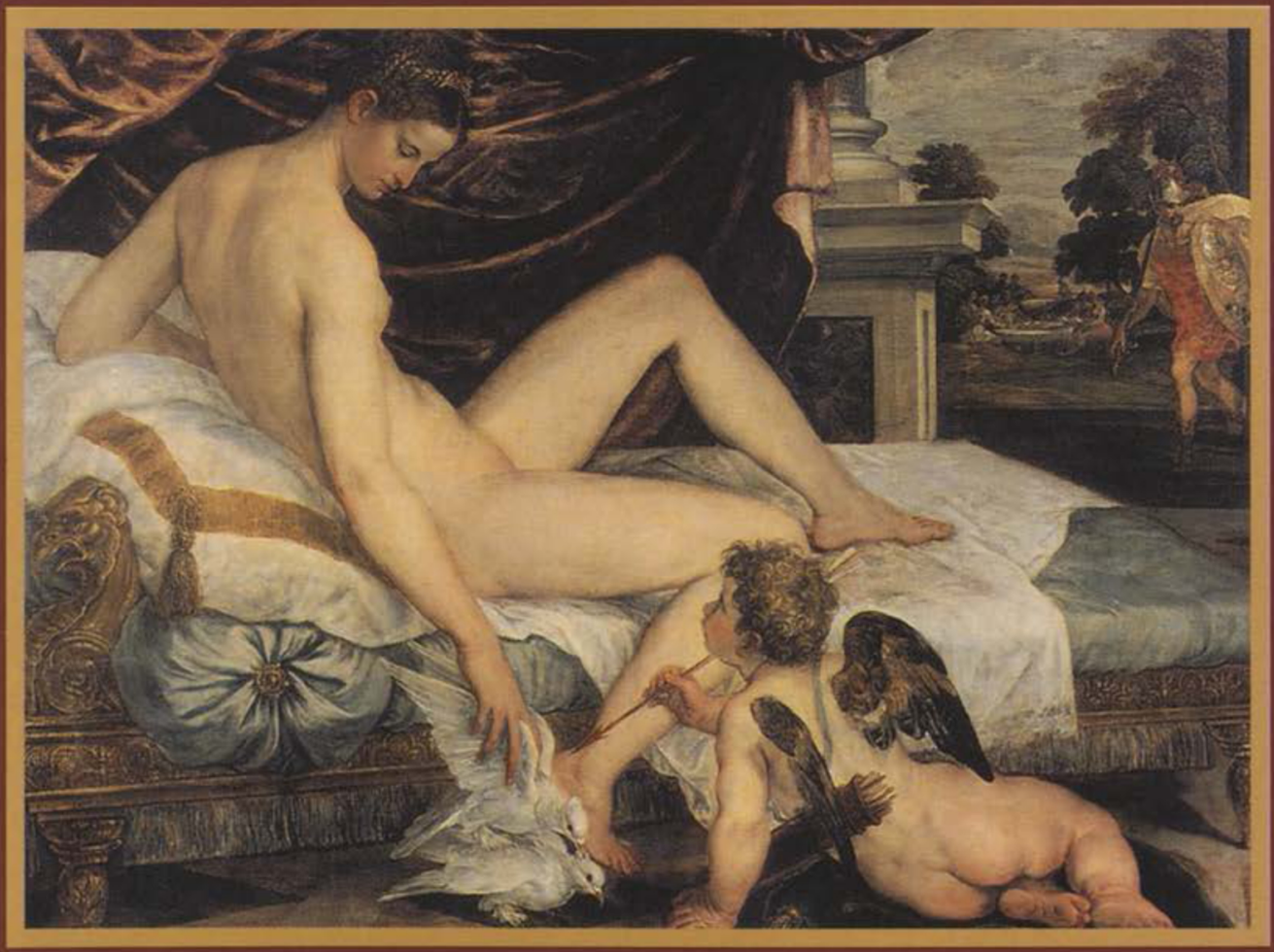

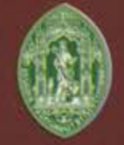

Universidade de Coimbra

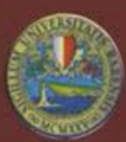

Università degli Studi di Bari

COIMBRA

2005 


\title{
AS HISTÓRIAS NO ASINUS AUREUS DE APULEIO E A SUA RELAÇÃO COM O ROMANCE
}

\author{
CLÁUdiA AMPARO AFONSO TEIXEIRA \\ Universidade de Évora
}

\begin{abstract}
The odyssey of Lucius integrates several stories, passible of grouping in two distinct narrative sets: the first one, formed by the story of 'Cupid and Psyche' and the episodes of Charite and Haemus/Tlepolemus; the second one, formed by the adultery and crime stories of books IX and X. In sharp contrast with the stories of adultery and crime - which, usually, agree to the ideological stadium of Lucius' manifest decay -, the first narratives offer euphoric examples of victories on the most varied forms of Fortuna's expression. Besides, those stories echo strong literary influences of well established genres, such as the heroic narrative, in the case of Haemus; the idyllic narrative in Cupid and Psyche story; the tragic one, in the outcome of the story of Charite and Tlepolemus. The conjugation of the literary nature of the texts with elements as the extension and the thematic, structural and syntactic organization, raises the issue about their definition in the Asinus aureus' structure. The present paper aims at showing how these stories don't represent narratives merely complementary of Lucius' odyssey, but state as central odysseys as this one - viewed, however, from the standpoint of the conventional values of the genre defining each one of them.
\end{abstract}

Bastaria uma pequena abordagem ao Asinus aureus de Apuleio para o leitor se aperceber da quantidade de histórias que integram o romance, histórias essas para as quais, aliás, se alerta imediatamente no prólogo do romance (1.1): sermone isto Milesio uarias fabulas conseram («vou entretecer, nesta toada milésia, histórias variadas»).

A consideração, ainda que generalista, destas fabulae uariae permite constatar a sua divisão em dois grandes grupos temáticos: o primeiro agrega as histórias da primeira etapa metamórfica do romance, como o conto de Amor e Psique e as histórias de Cárite e Hemo/ Tlepólemo; o segundo reúne o conjunto de histórias que dominam os livros IX e X, e que têm como centro temático o crime e o adultério.

Apesar de estas histórias apresentarem, na sua relação com o romance, uma estruturação que combina várias séries sequenciais, em 
que pequenos episódios, centrados no desenvolvimento da odisseia de Lúcio, alternam com um conjunto de episódios de extensão variável, não é possível deixar de notar o acentuado contraste ideológico entre os motivos que dominam as narrativas desses grupos. Com efeito, se as histórias do segundo grupo manifestam uma acomodação clara ao universo do romance, pois, ao incidirem tematicamente no tratamento de personagens representativas de determinadas patologias sociais, permitindo, deste modo, o desenvolvimento da narrativa através do contacto do herói com mundos ajustados à luz de uma sociedade eticamente marginal, não só concordam com o estádio ideológico da manifesta decadência de Lúcio, mas contribuem também para a ilustração das coordenadas do mundo degradado, caótico, desordenado e injusto pelo qual o herói se encontra em trânsito; já as narrativas do primeiro grupo, embora ofereçam elementos potencializadores de meditação sobre as causas subjacentes à queda do protagonista, nomeadamente sobre a curiositas (Psique), e sobre as circunstâncias regedoras do mundo em que se encontra, de que é exemplo a natureza destrutiva da Fortuna (Cárite e Tlepólemo), não deixam de se configurar como exemplos de vitórias sobre as mais variadas formas de expressão da Fortuna - vitórias que, no que respeita ao plano material do romance, apontam, efectivamente, para o desfecho da odisseia de Lúcio; e, no que respeita ao plano ideológico, para a solução religiosa expressa pela intervenção de Ísis.

No entanto, se, por um lado, as histórias de Psique, Cárite e Hemo / Tlepólemo se constituem como parte integrante da narrativa de Lúcio, por outro lado, estabelecem entre si uma não menos complexa teia de relações, agilizadas quer pelos universos temáticos que desenvolvem, quer pelas semelhanças estruturais - observadas, sobretudo, entre a de Psique e Cárite -, quer pelo complexo encadeamento das respectivas sintaxes diegéticas, formatadas, sucessivamente, em uma relação de dependência: é, com efeito, a angústia de Cárite que desencadeia a narração do conto de Amor e Psique; o sequestro dos ladrões motiva o aparecimento de Hemo; e os reveses que sofreram, em assaltos recentes, a aceitação do jovem na quadrilha; por sua vez, o resgate de Cárite assume-se como condição sine qua non para o desenrolar da sua própria história trágica.

A estes factores - suficientes para atrair à discussão o problema das centralidades do romance -, adiciona-se ainda o facto de, no quadro geral do Asinus aureus, estas narrativas ecoarem, por oposição ao realismo interno dos episódios accionais que envolvem Lúcio, influências literárias acentuadas, que as modelizam de acordo com determina- 
dos traços de géneros pré-consagrados, ou seja, a narrativa heróica, no caso de Hemo, a narrativa idílica, no conto de Amor e Psique, e a tragédia, no desfecho da história de Cárite e Tlepólemo.

Deste modo, a conjugação da natureza literária dos textos, intrinsecamente marcada por uma essencialidade valorativa, com factores como a extensão, a organização temática, estrutural e sintáctica, levanta o problema da definição das narrativas no quadro do romance: constituem estas narrativas meras estruturas formalmente complementares do percurso de Lúcio e, portanto, subsidiárias da linha que define o Asinus aureus como romance? Ou essa complementaridade traduz-se em uma apresentação de percursos semelhantes ao de Lúcio, equacionados, porém, à luz dos valores tradicionalmente associados ao género que os enforma?

\section{O conto de Amor e Psique}

A definição da função do conto de Amor e Psique no quadro do Asinus aureus de Apuleio implica, desde logo, uma tomada de posição relativamente à definição da matéria narrativa do conto - que, tal como a de Lúcio, desenvolve uma história de queda, agilizada pela curiositas da protagonista, e ascensão ontológica, promovida pela intervenção de uma divindade -, pois, o entendimento que dela se faz condiciona a sua ligação e o modo dessa ligação ao universo do romance.

Essa questão é indissociável do problema do estabelecimento das fontes literárias do conto. A discussão da crítica relativa a este problema tem manifestado a tendência para a aceitação de que o conto constitui uma reelaboração de versões tradicionais ${ }^{1}$ anteriores a Apu-

1 WALSH (1995), 377, define o conto como «a folk-tale with mythological additions»); WRIGHT (1971), 273-284, considera que a versão do conto de Apuleio assenta em uma longa tradição prévia, literariamente reelaborada; SCHLAM (1976) inclina-se para a consideração de que o conto representa uma versão elaborada de um conto tradicional, mas faz a retractatio dessa posição em SCHLAM (1993). Com base na análise das variantes, constata que «The plot of the Apuleian narrative (....) does not preserve any single and complete folktale»; e exemplifica a afirmação, idem, 66, com o facto de motivos como a intemporalidade expressa em Erant quadam ciuitate não constituir um topos exclusivo da narrativa tradicional; de igual forma, idem, 65 , «The report by Psyche's sisters that her husband is a monstrous snake, and her acceptance of this report, indicate the existence of the motiv, but do not make the tale an example of the monster-mate type.» Acrescenta ainda, ibidem, que o motivo da interdição «does not $(\ldots$.$) bring the story in Apuleius any closer to a single tale-type. Violation of the$ taboo is subordinate to the attack of the sisters in the first half of the Apuleian narrative 
leio, posição que assenta no reconhecimento de que a narrativa de Amor e Psique obedece, no plano da construção, à morfologia e sintaxe do conto tradicional e mitológico. Com efeito, motivos presentes no conto, como a beleza (que suscita inveja), o afastamento da casa paterna, o desconhecimento da verdadeira identidade do noivo, a interdição, o incumprimento dessa interdição, a separação decorrente da culpa, as provas e a união final constituem ${ }^{2}$ traços fundamentais do epos tradicional, cuja sintaxe permite uma organização em sequências variáveis.

Apesar do reconhecimento da presença estruturante desses motivos, a tessitura narrativa deixa perceber claramente uma intervenção literária do conto, que revela influências que assentam em tradições variadas, ${ }^{3}$ na literatura alexandrina, ${ }^{4}$ no romance grego, ${ }^{5}$ a que se juntam alguns elementos da milésia ${ }^{6}$ e ecos euripidianos. ${ }^{7}$ Embora estes

and it plays no role in the second half.» Este último dado não corresponde, no entanto, à quebra da interdição relativa à abertura da caixa em 6.20.

2 PROPP (1992); vide, a propósito da estrutura proppiana do conto de Amor e Psique, MANTERO (1973).

${ }_{3}^{3}$ Como, por exemplo, na tradição alegórica ocidental, visivel nos motivos do terror inspirado pela divindade aos humanos e no tema da expiação.

${ }^{4}$ De que são exemplos a presença de Pã na narrativa, bem como de outros motivos arcádios.

${ }^{5}$ Como os motivos da idealização da beleza de Psique e a vivência de aventuras com vista à superação de entraves ao enlace amoroso.

${ }^{6}$ Estes elementos são apontados como influências do conto por PARATORE (1995), 175-192, que assenta a sua argumentação na consideração de que é diminuta a influência da tradição popular no conto. No tocante às semelhanças do conto com o romance grego, parece-nos que a interpretação de BAKHTIN (1993), 216, afasta a definição do conto desse tipo de narrativa: «Se o problema fosse outro, se, por exemplo, como resultado das experiências e das aventuras vividas, a paixão inicial e repentinamente surgida entre os dois heróis tivesse ficado mais forte, tivesse superado problemas ou adquirido novas qualidades de amor sólido e experimentado, ou que os próprios heróis se tivessem tornado adultos e melhor conhecedores um do outro, então teríamos diante de nós um tipo de romance bastante avançado e bem diferente do romance de aventuras europeu e, em absoluto, não seria romance grego. Pois, nesse caso, embora os pólos do enredo permanecessem os mesmos (a paixão no início - o casamento no final), as próprias peripécias que retardam o casamento adquiririam sentido biográfico (....) ou talvez psicológico, apresentar-se-iam implicadas no tempo real da vida dos heróis, modificando-os (....). Mas no romance grego não acontece absolutamente nada disso: há um hiato puro entre os dois momentos do tempo biográfico, que não deixa nenhum vestígio no carácter e na vida dos heróis.»

${ }^{7}$ Elementos desenvolvidos por SMITH (1998), 69-82. HARRISON (1998), 51-68 , observa que a inserção do conto na narrativa é semelhante ao processo épico da narração a posteriori feita por Eneias e Ulisses na corte de Dido e de Alcínoo e estabelece paralelos entre a catábase de Psique e a catábase virgiliana. 
elementos contribuam para a criação de um ambiente cuja elaboração se encontram afastada do modelo do conto tradicional, verifica-se que não são, no entanto, suficientemente expressivos para a definição do conto fora das fronteiras do quadro narrativo de teor mitológico.

Com efeito, e apesar das semelhanças de forma entre os dois universos ficcionais, são bem distintos os traços de conteúdo. Se na odisseia de Lúcio o colapso entre ficção e realidade (determinado, entre outros elementos, pelo carácter fantástico da metamorfose) é compensado pela complexidade de vozes e de pontos de vista que se fazem sentir ao longo do romance, pela feição problemática do herói e pela presença de um estrato civilizacional, patente quer nas histórias de crime e adultério, quer nos juízos relativos à justiça e à religião, quer na expressão do modo de vida dos interlocutores -, o ambiente da narrativa de Amor e Psique, ao assentar a sua estrutura no mito, desenvolve uma representação ideal e idealizada de um percurso sublimado estruturado à luz de uma certa idealização demonstrativa.

No entanto, estas diferenças - que configuram uma história de natureza bem distinta - não constituem obstáculo a que o conto, precisamente porque beneficia do potencial infinito do mito para se constituir como recurso alegórico, ${ }^{8}$ agilize um amplo quadro de relações temáticas, estruturais e conceptuais com a narrativa principal, actualizado nos inúmeros paralelos observados entre as histórias de queda e ascensão de Psique e de Lúcio.

Os paralelos enunciados evidenciam que o conto em muito ultrapassa $^{9}$ a função enunciada (forma de consolo a Cárite) no plano imediato da narrativa. ${ }^{10} \mathrm{Com}$ efeito, apesar de consistir em uma estrutura naturalmente condensada, o conto de Amor e Psique exprime as coordenadas de uma saga problemática semelhante à que Lúcio vive no romance. De um ponto de vista simbólico, conto e romance encontram-se enquadrados por um substrato platónico, que ecoa a alegoria da ascensão da alma ao divino através do amor (Phaed. 246a - 257b;

${ }^{8}$ Usamos o termo 'alegórico' em sentido clássico, ou seja, na acepção em que o termo se afirma como "trazer em simultâneo» (de symballein), tanto na perspectiva do conto em relação ao seu significado, como na perspectiva do significado do conto em relação ao significado do romance.

${ }^{9}$ Como o indiciariam, logo a priori, a posição central que ocupa no romance e a extensão de quase três livros.

${ }^{10}$ As palavras que introduzem o conto, (4.27) sed ego te narrationibus lepidis anilibusque fabulis protinus euocabo («Pois bem: eu vou agora atrair-te a atenção com histórias divertidas e contarelos de velha») ecoam as palavras do prólogo do romance (1.1): At ego tibi sermone Milesio uarias fabulas conseram («vou entretecer, nesta toada milésia, histórias variadas». 
Symp. 201d-212c); e, em ambos os casos, o plano ascensional desenvolve-se através dos tempos que expressam os 'momentos de crise' de cada protagonista. ${ }^{11}$ No entanto, esses paralelos ${ }^{12}$ ultrapassam o enquadramento temático que desenvolve o tema da queda e ascensão e estendem-se ao próprio desenvolvimento material das histórias: «There are notable similarities between Lucius and Psyche as hero and heroine of their respective stories. Both are distinguish origins, which avail them nothing. (....) Each is exposed to the assaults of a malignant Fortune (....) in a hostile and uncaring world. Both are saved in the end by the undeserved intervention of divine grace. (....) In both stories the theme of improspera curiositas is central. Both human protagonists obstinately persist in the path to ruin, blind and deaf to repeated warnings, direct in Psyche's case, indirect for the most part in Lucius' (....). Both submit to a goddess and are required to undergo ordeals, which lead to a final state of union, in Psyche's case with Love, in Lucius case (mystically) with Isis, who among other things is Venus caelestis (...). As part of their ordeals each undergoes a kind of death in the course of a descent to the Underworld, physical in Psyche's case, symbolic in Lucius'. The outcome of both unions is Voluptas (....). The divine protagonist of both stories shade, so to say, into one another. Venus appears in book XI as one of the guises of Isis, who is also identified with both Fortuna and Prouidentia.»> ${ }^{13}$

A última queda de Psique, novamente motivada pela curiositas, antecipa o estádio ideológico de Lúcio antes da salvação e a ideia de que a caminhada obrigatória (como consequência dos erros cometidos) e intrinsecamente marcada pelo erro não é susceptível de, per se, promover a aprendizagem necessária ao resgate dos erros e das condições em que caíram os heróis. O preceito acomoda-se, no entanto, à tipologia da narrativa de salvação, na qual a ideologia reflecte, antes de mais, as rupturas, as desuniões e as crises da própria vida, semeadas de impasses internos e individuais, ou seja, as etapas da vivência do

${ }^{11}$ A exegese da leitura neoplatónica do conto pode ver-se em DOWDEN (1982). A análise do conto, em RAMBAUX (1995). Sobre a representação do conto na arte visual, vide MAASKANT-KLEIBRINK (1990).

${ }_{12}$ Também em relação ao plano transcendente do romance a narrativa agiliza paralelos religiosos, visíveis nos ecos isíacos presentes na história, de que são exemplo os motivos da inveja das irmãs, subjacentes à separação, a odisseia de Psique em busca de Cupido, e a vitória final sobre a adversidade. Esses paralelos evidenciam-se no motivo da destruição de Osíris pelo irmão, Set (que aspirava à posição de deus supremo), bem como na odisseia que Ísis realiza para encontrar Osíris e na ressurreição que the proporciona.

${ }^{13}$ KENNEY (1990), 13-16. 
homem sob a forma de experiências, ${ }^{14}$ e não a sua transformação em definitivo, possibilitada apenas pela divindade.

Neste sentido, o que as longas caminhadas do conto e romance manifestam é a ideia de que a reconstituição do ideal (que, no caso de Psique, se centra no Amor e, no de Lúcio, na recuperação da figura humana) não é apanágio do ser errante. A este compete apenas (e neste ponto, a odisseia de Lúcio é muito mais expressiva do que a de Psique) o desejo de recepção do benefício que, no caso dos dois heróis apuleianos, se amplia na subsequente fusão da vida humana com a vida da divindade - e só então se completa a viagem que assenta no topos da imagem do homem, alegoricamente desenvolvida à luz dos motivos da transformação e da identidade. Deste pressuposto, nascem, no conto, Voluptas, e, no romance, a alegria expressa nas palavras do fecho: gaudens obibam.

No que respeita ao destino de Lúcio, apesar de o conto de Amor e Psique evidenciar uma função promotora de auto-reflexividade, a reacção à história por parte do herói inscreve-se em uma linha estritamente sensorial (6.25): Sed astans ego non procul dolebam mehercules quod pugillares et stilum non habebam qui tam bellam fabellam praenotarem («Eu estava não muito longe e, palavra, lamentava não ter tabuinhas e estilete para registar tão bela historieta.»).

\section{A história de Cárite e Hemo/Tlepólemo}

O desfecho do conto de Amor e Psique marca o regresso da narrativa à odisseia de Lúcio. Os ladrões voltam ao covil e levam o burro para servir de transporte a mais mercadoria roubada. A prestação do herói é fraca e os salteadores resolvem matá-lo no dia seguinte. Mais tarde, depois de uma tentativa frustrada de fuga com Cárite, o mesmo ladrão que anunciara a atribuição do assalto a Lúcio traz uma nova aquisição para a quadrilha, Hemo. Hemo apresenta-se como um ladrão trácio, cujo bando tinha sido aniquilado pela intervenção de uma mulher, Plotina, que, disfarçada de homem, acompanhara o marido no exílio. Quando são dizimados pela quadrilha, Plotina implora a César o desmantelamento do bando. Só Hemo escapara ao ataque dos soldados,

${ }^{14}$ Veja-se, a este respeito, a afirmação de Lúcio em 9.13, diferida e disjuntiva do contexto, na qual agradece à figura asinina o ter-lhe permitido tornar-se multiscius, adjectivo cujo significado se liga às experiências vividas (uariisque fortunis exercitatum) e não a qualquer espécie de transformação ontológica. 
porque, disfarçado de mulher, conseguira passar pela guarda sem ser reconhecido. ${ }^{15} \mathrm{~A}$ narrativa das proezas do trácio vale-lhe a consideração dos ladrões e a consequente eleição para chefe do bando. Hemo, que afinal era Tlepólemo, o noivo de Cárite, oferece um banquete aos novos companheiros, embriagaos convivas e salva a donzela, que entra na cidade sentada sobre o dorso de Lúcio. Tlepólemo regressa, acompanhado por Lúcio e por alguns populares, à gruta e aniquila o bando.

A detecção do significado da história de Hemo beneficia, no entanto, da consideração paralela das histórias dos ladrões, narradas anteriormente, no livro IV (4. 9-21). Na primeira, conta-se o assalto à casa de Críseros. Durante o arrombamento, o chefe dos ladrões, Lâmaco, fica com o braço preso na porta. Os sócios cortam-lhe o braço, para que possa fugir. No entanto, durante a fuga, o ferido não consegue acompanhar os restantes; e, para não comprometer os companheiros, suicida-se. Na segunda história, narra-se o assalto a casa de uma idosa. Como o ladrão atirava o produto do saque pela janela, a dona da casa convence-o de que os vizinhos, no exterior da casa, beneficiavam do roubo. O salteador, intrigado, assoma à janela; a dona da casa empurra-o e o ladrão morre da queda. A terceira história conta que Trasileão, disfarçado de urso, se introduzira em casa de um rico homem, de forma a poder abrir a porta aos restantes durante a noite. Mas um dos criados, pensando tratar-se de uma fera à solta pela casa, atiça-lhe os cães de caça. Trasileão, para não denunciar os companheiros, suporta todos os golpes, e acaba por morrer, trespassado por uma lança. As histórias dos ladrões constituem, nesta fase do romance, o primeiro exemplo de narrativas às quais subjazem influências literárias acentuadas. Na verdade, apesar de apresentarem alguns elementos de natureza popular, todas as narrativas manifestam a presença de traços distintivos das narrativas épicas. Além de elementos como a recitação a posteriori, em contexto de banquete, Cooper, ${ }^{16}$ observa que «It is highly significant that throughout this book the thieves are characterized as epic heroes, clothed traditionally have been thought most admirable. Lamachus, the leader lost in the "siege" of "seven-gated Thebes"

15 FRANGOULIDIS (1994a), 346-347, observa que «In this respect Tlepolemus' fictional tale of Plotina can be seen as thematically relating to the narrative within which it is inserted and, in a way, as foreshadowing the fate that awaits the brigands. Unlike the attentive listeners/readers, however, the tale's internal audience, the robbers, fail to draw a connection between Plotina's disguise and that of pseudo-Haemus (....).»

${ }^{16}$ COOPER (1980), 441-442. 
[Thebas heptapylos - 4.9] during the "attack" on Chryseros, is wonderfully described as a virtuous hero and leader of his "troops" [4.10]. In his extremity Lamachus exhorts his men to kill him per fidem sacramenti [4.11], an act which his noble and scrupulous band of thieves eschew. (....) Similarly, Thrasyleon receives from one of his comrades the following grandiloquent salute, totally befitting a hero, but appropriate to his own character only within the peculiar environment of Apuleian morality, where hero and thief are one: 'sic etiam Thrasyleon nobis periuit, sed a gloria non periuit $[4.21 \ll \mathrm{E}$, assim, Trasilo pereceu para nós, mas não pereceu a sua glória»].» A crítica aponta ainda semelhanças entre o disfarce de Trasilo, descrito como anceps machina, e a ocultação dos guerreiros gregos, dentro do cavalo, descrito, na Eneida, como fatalis machina.

De igual modo, também a intervenção de Hemo apresenta, segundo a crítica, elementos característicos do universo épico, ${ }^{17}$ sobretudo da Iliupersis virgiliana. Além da linguagem épica, característica que partilha com as restantes histórias, o próprio nome do herói (um nome plurissignificativo) ecoa o de uma famosa montanha, ${ }^{18}$ elemento que estabelece um paralelo com a descrição da face material do perigo grego na Eneida, uma vez que os Gregos instar montis equum (....)

${ }^{17}$ FRANGOULIDIS (1992), 73, sustenta que «(...) Apuleius (....) has composed a tale that incorporates features of an epic narrative: the heroic theme of abduction and the subsequent punishment for her unjust captivity; the epic motif of trickery and disguise, etc.». O crítico observa ainda, idem, 61, paralelos entre o episódio de Hemo e o de Polifemo na Odisseia: "What has not been properly assessed, however, is that the scenery of the cave, the emphasis on Tlepolemus' cleverness and trickery which suggested a Vergilian comparison, and the strategy of the execution of the robbers' band may point to a comparison with Homer's description of Odysseus' punishment of the Cyclops and his safe exit from the cave. Further, the Homeric hero employed wine in his plan to blind Polyphemus and, thereby, achieve a safe escape for himself and his companions from the monster's cave.» E atribui a presença da referida evocação a um reflexo da admiração de Lúcio, expresso em 9.13, «for the diuinus auctor of the genre». No entanto, e apesar dessa admiração, idem, 73, «(...) these epic motifs and echoes receive such a treatment in the novel as to call attention to the incompatible and inverted development within their new literary environment in comparison to their handling in the original setting.» Relativamente à formulação épica, e apesar da evidência dos paralelos, a transcontextualização dos elementos para o romance implica que ocorram não em situações épicas (porquanto esta narrativa implica um enquadramento ideológico e situacional diferente do enquadramento do romance), mas apenas heróicas (situações cuja estruturação partilha motivos com a narrativa épica, e de que são exemplo os motivos da superação, do sacrificio, da caracterização física dos intervenientes, da capacidade de gestão bélica).

${ }^{18}$ HIJMANS (1978), 408. 
aedificant (En. 2.15 «constroem um cavalo alto como uma montanha»); de igual forma, os Troianos, depois de trazerem o cavalo para dentro da cidadela, festejam o suposto fim da guerra e embriagam-se (En. 2.265 urbem somno uinoque sepultam «cidade amortalhada pelo sono e pelo vinho»); também os ladrões, depois de acolherem Hemo dentro da caverna e de o proclamarem chefe do bando, ${ }^{19}$ seguem o mesmo processo; os Troianos morrem à mãos dos Gregos que, em virtude do êxito do estratagema, entram na cidade parati neci (En. 2.333 «preparados para matar») e os ladrões, parati morti, morrem às mãos de Tlepólemo e dos seus ajudantes. ${ }^{20}$

Em universos temáticos e estruturais análogos (sobretudo no que toca às intervenções de Hemo e Trasileão) ${ }^{21}$ ressalta como elemento distintivo entre as histórias a dissensão entre a forma eufórica como se conclui a intervenção de Hemo, por oposição ao inêxito que traduz o desfecho das histórias do livro IV. A interpretação de diferentes desfechos para padrões de acções semelhantes tem sido entendida de forma variável, com extensões centradas no 'efeito cómico', gerado pela aplicação de elementos heróicos a personagens que se revelam vulgares ladrões; ${ }^{22}$ e interpretações concordantes com o universo ético do romance, que determina o castigo dos ladrões, porquanto símbolos

19 FRANGOULIDIS (1994a), 344-345, aponta uma diferença de natureza accional para a justificação da vitória de Hemo e para a derrota de Trasileão: «This insistence of Thrasyleon on maintaining his bear disguise contrasts most sharply with Tlepolemus' tactic within the robbers cave. On becoming their chief, Tlepolemus takes a new role. Such an assumption of a new persona becomes clear in the context where Tlepolemus puts on the outfit which the robbers offer to him, when they inaugurate him as their chief. (....). This outfit transforms him (....) It is precisely in this new role that Tlepolemus puts into effect his trickery of drugging the robbers to sleep with wine, liberates his bride from captivity, and, unlike Thrasyleon, safely exits the cave (....).»

${ }^{20}$ FRANGOULIDIS (1992), 60, conclui, a respeito da influência literária do episódio, que «It is not impossible, therefore, that Charite's recapture constitutes an imitatio cum uariatione of Vergil's description of the capture of Troy.»

${ }^{21}$ FRANGOULIDIS (1994a), 345, centra-se, sobretudo, no motivo dos disfarce e da mutação dos papéis das personagens, para estabelecer conexões entre as histórias: «Tlepolemus impersonates a renown criminal, Haemus, in order to assume the leadership of the brigands and then liberate his bride from captivity in the robber's cave. Likewise, the bandit Thrasyleon willingly assumes an animal disguise in order to penetrate Demochares' house, let in the rest of the company of his comrades, and then plunger it. (....). The tale's own audience, the robbers, however, fail to note this connection, and thus to gain an understanding of the new recruit's disguise and intentions.»

${ }^{22}$ ESPOSITO (1989), 306-322. 
representativos do mundo desordenado, e o êxito de Hemo, por se constituir símbolo da tentativa de ordenação desse mesmo mundo. ${ }^{23}$

$\mathrm{Se}$, em primeira análise, as diferenças parecem, efectivamente, decorrer dos motivos accionais valorativos que presidem aos vários episódios, marginais no que respeita aos ladrões, de feição antimarginal no que respeita a Hemo, o posterior desenvolvimento do destino do herói levanta novos problemas, que alargam a interpretação das histórias à contextura ético-moral expressa pelo romance.

No entanto, no que respeita ao plano global do romance, o que resulta desta primeira fase da história - em que o resgate de Cárite, tal como a subida ao Olimpo por parte de Psique, constitui, efectivamente, um êxito -, é uma mensagem de vitória sobre a adversidade, em um contexto onde, de acordo com os princípios que presidem ao universo do romance, não deveriam (tal como sucede nos livros IX e X) existir vitórias. Este factor parece legitimar a opinião de que à primeira e segunda etapas do ciclo metamórfico correspondem não só diferentes níveis de estruturação dos episódios, mas também diferentes objectivos relativamente à expressão do plano ideológico.

Um mensageiro vem anunciar o desfecho trágico da história da jovem. Depois do casamento, um dos antigos pretendentes de Cárite, Trasilo, aproveita uma caçada para simular um acidente e assassinar Tlepólemo. Inspirada por um sonho em que Tlepólemo the narra os acontecimentos da sua morte, resolve vingar-se. Convida Trasilo para um encontro nocturno, manda servir um vinho soporífero ao assassino e, quando este adormece, trespassa-lhe os olhos. Depois corre para o túmulo do marido e crava no peito a espada de Tlepólemo. Cárite é restituída ao marido como perpetua coniux (8.14). Trasilo encerra-se no mesmo túmulo e autocondena-se à morte por inanição.

Embora a história de Cárite se desenvolva, tal como a de Psique ${ }^{24}$ à volta de um eixo temático centrado no binómio 'perda e reconquista',

${ }^{23}$ GIANOTTI (1986), 59-83.

24 BARRETT (1994), 74-75, observa que "Charite (from the Greek charis, meaning 'grace' or 'charm') and Psyche (soul) are beautiful woman who are destined to marry. In Greek iconography, Charite often replaces Psyche as the bride of Cupid. Both are torn away against their wills on their wedding day and become unwilling guests of their male captors. (....) Charite is literally torn from her mother's arms by the robbers (4.26) who imprison her in a cave. She is a helpless captive who fears, for good reason, that she will be either murdered or held for ransom by the robbers. As directed by an oracle, Psyche is left by her family on a cliff as a sacrificial bride to a terrible monster (4-33-35). (....) Her sisters warn her that her suitor may indeed be the devouring serpent that they all feared.» 
não é possível evitar a constatação da aparente inversão traduzida pelo desfecho das narrativas, ou seja, a sublimação de Psique e a morte, em circunstâncias trágicas, de Cárite. ${ }^{25}$

A presença de elementos trágicos na história de Cárite tem sido entendida de forma muito distinta pela crítica: ${ }^{26}$ eco virgiliano da história de Dido, ${ }^{27}$ reminiscência das tragédias sofoclianas, ${ }^{28}$ exemplo de desintegração de personalidade, ${ }^{29}$ em sentido mais moderno, constituem elementos de interpretação da história.

Pensamos, no entanto, que, apesar das múltiplas referências e ecos literários presentes na narrativa de Cárite, é na dimensão apologética da obra que a acção da heroína, bem como as várias transformações pelas quais a sua história vai passando, encontram significado pleno. Com efeito, a aceitação da circunstância de que o Asinus aureus constitui uma obra de matriz religiosa, implica a consideração de que a acção de Cárite, após a morte de Tlepólemo (em condições muito

${ }^{25}$ A profunda diferença entre os destinos das heroinas mais evidente se torna, caso se tenham em consideração os antecedentes accionais das personagens, que assentam em uma distinção entre o erro de Psique, a curiositas (reiterado, novamente, antes da redenção), e a ausência de erro, no tocante a Cárite.

${ }^{26}$ BRANDÃO (1996), 183-195, analisa o carácter trágico do episódio em perspectiva formal, e evidencia a possibilidade da dramatização do episódio em quatro actos. COOPER (1980), 448, entende a existência de uma linha de condenação da violência associada às acções de Cárite e também de Tlepólemo. Deste modo, o destino das personagens evidenciaria a condenação de Apuleio relativamente à moral agressiva típica da épica que define ambas as personagens: «In so doing, (....) Apuleius negate the moral validity of the aggressive action which characterizes epic (....).» e idem, 456-457, observa que "Once more, Apuleius is assuring us that aggressive action, whether performed by a man or a woman and whether given masculine or feminine associations, only gives the appearance of being at times justifiable when in fact it is never to be morally condoned. To attribute this kind of moral guilt to such sympathetically drawn characters as Tlepolemus and Charite (...), surely contradicts the reader's positive emotional response towards them. If one considers, however, the author's evangelical and didactic intent, it becomes evident that Apuleius must have considered himself to be drawing on his own superior religious insight in order to show the typical, unenlightened reader that the ordinary standards of good and evil, innocence and guilt are not truly valid.» Discordamos desta posição, nomeadamente no que toca à associação que se faz entre a natureza da acção de Cárite após a morte de Tlepólemo e a acção épica. Com efeito, os motivos da vingança e da violência não constituem, em essência, elementos exclusivamente épicos.

${ }^{27}$ HARRISON (1996), 516.

${ }^{28}$ WALSH (1995), 164.

${ }^{29}$ SHUMATE (1995), 110-111. 
semelhantes à de Osíris), ${ }^{30}$ se aproxima da própria saga isíaca, na qual a morte do deus catalisa uma modificação do papel da deusa: se, em fase inicial, coube a Osíris pacificar a terra, depois da sua morte, é Ísis quem protagoniza a saga divina da vingança e da ressurreição do deus. Desta forma, a acção de Cárite parece acomodar-se ao sentido da acção de Ísis, após a morte de Osíris. Além disso, também o desfecho da narrativa divina e da narrativa de Cárite apresentam valências de significado. Com efeito, o desenlace da narrativa de Ísis determina que os valores de referência associados aos deuses adquiram, fruto do abandono do mundo terreno por parte de Osíris, valores espirituais que amplificam o papel da divindade na sua relação com o homem: «In Egyptian religious thought it was not the earthly rule of Osiris that was significant but the miracle of his resurrection from death, offering the hope of a continuity of existence for everyone in the underworld $(\ldots.) .{ }^{31}$

Esta ideia parece aplicar-se ao sentido da história trágica de Cárite. Com efeito, o compromisso de reparação, resultante da possibilidade de redenção em contexto post mortem, evidenciado pela expressão perpetua coniux, apresenta-se como solução resgatadora da inexorabilidade do sofrimento, promovido pela intervenção, na vida humana, do caos e da violência, elementos que decorrem, simultaneamente, do contexto ideológico da acção da Fortuna (associada a Trasilo, na história de Cárite) e da divindade opositora, Set, à tríade sagrada egípcia (na narrativa de Ísis). ${ }^{32}$

${ }^{30}$ Sobre os elementos que concorrem para a definição de Tlepólemo como hipóstase de Osíris, vide HIJMANS (1986), 407-414; GRIFFITHS (1975), 141-166, esp. 152 e seg.; TEIXEIRA (2000), 93-95.

${ }^{31} \operatorname{HART}(1990), 33$.

${ }^{32}$ De igual modo, e a despeito da autocondenação à morte por parte de Trasilo, a noção de justiça divina aplica-se com maior premência do que o castigo terreno. Significativas a esse respeito são as palavras que Cárite lhe dirige no momento em que Ihe decreta a punição (8.12): Lumen certe non uidebis, manu comitis indigebis, Chariten non tenebis, nuptias non frueris, nec mortis quiete recreaberis, nec uitae uoluptate laetaberis, sed incertum simulacrum errabis inter Orcum et Solem. («Não mais verás a luz, necessitarás da mão de um companheiro, não possuirás Cárite, não gozarás as núpcias, nem fruirás do descanso da morte, nem te alegrarás com os prazeres da vida, mas como um espectro incerto vaguearás entre o Orco e o Sol.») As palavras com que Cárite anuncia a punição (utilizadas, em sentido inverso, no ritual iniciático da religião isíaca) enquadram-se igualmente na linha de expressão do compromisso, na medida em que demonstram, mais do que o castigo terreno, a futura condição espiritual do assassino. Como referem os comentadores de Gröningen (Cit. por GRANWEHR (1994), 113), tais palavras expressam a impossibilidade de recompensa para o criminoso, pois significam que «As a kind of ghost wandering 
Embora a metamorfose, no tocante a Lúcio, tenha dado lugar à expressão do mundo da Fortuna caeca, é, contudo, verdade que, ao longo dessa odisseia, o eixo temático decorrente da acção daquela entidade se alarga à expressão dos seus efeitos em quadros mais amplos. Os mais expressivos desses quadros foram os desenhados pelas narrativas de Psique e Cárite, nos quais as inversões que se actualizam nos percursos das heroínas testemunham a fragilidade da condição humana, perspectivada em termos individuais, na sua relação com os elementos portadores de caos e violência que atravessam o mundo quotidiano; um mundo que, na sua essência, se revela desordenado, e ao qual só o contacto com a verdadeira divindade trará, simultaneamente, consolo e ordenação.

A natureza sistemática destes elementos sugere a constatação de que os percursos das narrativas que ocupam a primeira etapa do ciclo metamórfico, porquanto evidenciam um efectivo paralelismo com o percurso de Lúcio - todas se estruturam mediante o binómio queda e ascensão e todas evidenciam um triunfo espiritual, expresso de diferentes formas, sobre as contingências materiais da vida e da Fortuna -, se constituem, não apenas como subsidiárias da narrativa principal, mas como percursos tão centrais como a própria odisseia do herói. De igual forma, o desenvolvimento dessas narrativas à luz de motivos

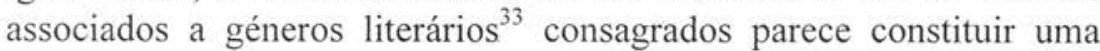
estratégia que visa equacionar também os próprios valores definidores desses géneros. Com efeito, não é possível deixar de constatar que, em todas as histórias, se verifica um profundo dissídio entre os conflitos apresentados - desenvolvidos à luz dos elementos característicos dos géneros literários que enformam cada uma das histórias - e o resgate dos quadros de falência que lhes sobrevêm por elementos que, no seu conjunto, apontam para uma moral redentora própria e exclusiva do romance: em Psique, a falência do idílio é resgatada pela intervenção da divindade clarividente (refiguradora do sentido da divindade tradicional); a precariedade do êxito de Hemo e Cárite, materializada no desfecho trágico da sua vida, resulta compensada de forma ajustada ao

between the underworld and the true light, Thrasyllus was physically and spiritually blind, because $[. . .$.$] he would not be granted the redeeming spiritual insight (....).»$

${ }^{33}$ A transcontextualização de elementos de outros géneros para a tessitura do romance obriga, no entanto, ao ajustamento dos elementos centrais de cada história às características da narrativa, como o evidenciam o facto de a intervenção de Tlepólemo, apesar das semelhanças com o livro II da Eneida, traduzir uma narrativa mais heróica do que épica, e o facto de a história de Cárite aproveitar da matriz trágica apenas alguns motivos. 
que se passa na narrativa divina de Ísis e Osíris; e a ausência de redenção, no tocante aos ladrões e a Trasilo, personagens que não evidenciam qualquer ligação ao elemento religioso, manifesta, ex inverso, a expressão dos efeitos de uma ordem sem divindade.

Neste sentido, talvez seja possível considerar que estas histórias expõem a convicção de que a moral, situacional e ideológica, típica de modelos de vida desenvolvidos pelos géneros literários que evocam, deixa de constituir resposta para a vida humana. A sua dimensão de exemplum (ou seja, a sua constituição como modelos de uma ética e de uma moral que deveria favorecer o desejo de imitação por parte dos humanos) sai, deste modo, derrogado, no romance de Apuleio, em benefício de outro valor, actualizado pelos desfechos das histórias; desfechos que - como bem o traduzem as redenções de Psique e de Cárite - não são mais do que representações simbólicas (inatingidas pela percepção de Lúcio) da única alternativa válida que o romance vai acabar por expressar, de forma clara e explícita, no último livro do romance.

\section{Bibliografia}

BAKHTIN, Mikhail, Questões de literaura e de estética. A teoria do romance (trad. BERNARDINI, Aurora et alii, São Paulo, UNESP, 1993).

BARRETT, Conrad, "The marriages of Charite and Psiche in the context of Apuleius' Metamorphoses", CB 70 (1994) 73-88.

BRANDÃO, J. L., "O romance de Cárite: uma tragédia em quatro actos”, Humanitas 48 (1996) 183-195.

COOPER, Gail, "Sexual and ethical reversal in Apuleius: the Metamorphoses as anti-epic", in C. Deroux (ed.) Studies in Latin literature and history (Bruxelles, Latomus-Les Belles Lettres, 1980) 436-466.

DOWDEN, Ken, "Psiche on the rock", Latomus 41 (1982) 336-352.

ESPOSITO, P., "Riuso e stravolgimento in Apuleio", Vichiana 18 (1989) 306-322.

FRANGOULIDIS, Stavros, "“Charite dulcissima': a note on the nameless Charite at Apuleius' Metamorphoses 7.12 (163.10)", Mnemosyne 44 (1991) 387-394.

tale of Thrasyleon", PP 258 (1991) 95-111.

, "Vergil's tale of the Trojan horse in Apuleius' robber, "Epic inversion in Apuleius' tale of TlepolemusHaemus", Mnemosyne 45 (1992) 60-74. 
, "The somnus funestus and sommus uanus of Charite: Apuleius, Met. 4.27 (95.16)”, Latomus 52 (1993) 105-111.

, 'Self-imitation in Apuleius' tales of Tlepolemus/ Haemus and Thrasyleon", Mnemosyne 47 (1994) 337-348.

and Psyche", CB 70 (1994) 67-72.

, 'Role-changing in Apuleius' tale of the Miller's wife (Metamorphoses 9.14-31)”, Scholia 9 (2000) 66-77.

(Stuttgart. Weimer, 2001).

Roles and performances in Apulieus' Metamorphoses

GIANOTTI, G. F., 'Romanzo' e ideologia. Studi sulle Metamorfosi di Apuleio (Napoli, Liguori, 1986).

GRANWEHR, M. Gabriela, Apuleius Metamorphoses: a study on structure (tese polic., University of Iowa, 1994).

GRIFFITHS, J. GWYN, Apuleius of Madaurus, The Isis-book - Metamorphses, book XI, (Leiden, Brill, 1975).

GRIFFITHS, "Isis in the Metamorphoses of Apuleius", Aspects of Apuleius' Golden Ass (Groningen, Bouma, 1975) 141-166.

HARRISON, “Apuleius' Metamorphoses", in G. Schmeling (ed.), The novel in ancient world (Leiden - New-York, Brill) 506-56.

HARRISON, S. J., "Some epic structures in Cupid and Psyche", Aspects of Apuleius Golden Ass 2 (Groningen, 1998) 51-68.

HART, JORGE, Egyptian myths (London, British Museum Publications, 1990).

HIJMANS, B. L., "Haemus, the bloody brigand (or: What's in an alias ?)", Mnemosyne 31 (1978) 407-414.

$350-364$.

, "Charite worships Tlepolemus-Liber", Mnemosyne 34 (1986)

KENNEY, E. J., Apuleius Cupid and Psyche (Cambridge, C. University Press, 1990).

MAASKANT-KLEIBRINK, "Psyche's birth", GCN 3 (1990) 13-33.

MANTERO, Teresa, Amore e Psique. Struttura di un fiaba di magia (Genova, Istituto di Filologia Classica e Medievale, 1973).

PARATORE, "La favola di Amore e Psiche in Apuleio", Storia, letteratura e arte a Roma nel secondo secolo dopo Cristo. Atti del conevgno Mantova 1992 (Firenze, 1995) 175-192.

PROPP, Vladimir, Morfologia do conto (trad. port., Lisboa, Veja, 1992).

RAMBAUX, C., Trois analyses de l'amour (Paris, Les Belles Lettres, 1995) 177-210.

SCHLAM , Carl, "Cupid and Psyche: folktale and literary narrative", GCN 5 (1993) 63-73. 
SHUMATE, Crisis and conversion in Apuleius' Metamorphoses (Michigan, UMP, 1995).

SMITH, "Cupid and Psyche tale: Mirror of the novel", Aspects of Apuleius Golden Ass 2 (Groningen, 1998) 69-82.

TEIXEIRA, Cláudia, A conquista da alegria. Estratégia apologética no romance de Apuleio (Lisboa, Edições 70, 2000).

WALSH, The roman novel. The Satyricon of Petronius and the Metamorphoses of Apuleius (Cambridge, CUP, 1070; reimp. Bristol, University Press, 1995).

WRIGHT, J. R. G. "Folktale and literary technique in Cupid and Psyche", CQ 21 (1971) 273-284. 